\title{
Case report: foreign body in male penile urethra
}

\author{
A F F Ghaly, A R Munishankar, S R Sultana, M Nimmo
}

\section{Introduction}

A penile urethral foreign body is rarely presented at departments of genitourinary medicine. It represents, however, one of the differential diagnoses of non specific urethritis. Patients frequently feel embarrassed and tend to ignore seeking immediate medical advice. The motive of inserting objects into the urethra remains difficult to comprehend. Eroticism and sexual experimentation fantasies appear to be the main desires of those patients. ${ }^{1}$ This is a report on one of the rare cases of a penile urethral foreign body lying dormant for 12 years, and eventually giving rise to urethritis-like symptoms.

\section{Case report}

A white, male Caucasian, manual worker, aged 36 years presented in April 1995 to the Department of Genito-Urinary Medicine at Dundee Royal Infirmary with a history of urethral discharge of one week's duration, together with dysuria and slight haematuria. His urinary stream was satisfactory without terminal spraying. He gave no history of previous sexually transmitted diseases. He had a

Department of Genitourinary Medicine, Dundee Teaching Hospitals NHS Trust, Dundee

Royal Infirmay, Dundee DD1 9ND, UK A F F Ghaly

A R Munishankar

Department of Urology S R Sultana

Department of

Radiology

M Nimmo

Correspondence to:

Dr A F F Ghaly.

Accepted for publication

3 October 1995

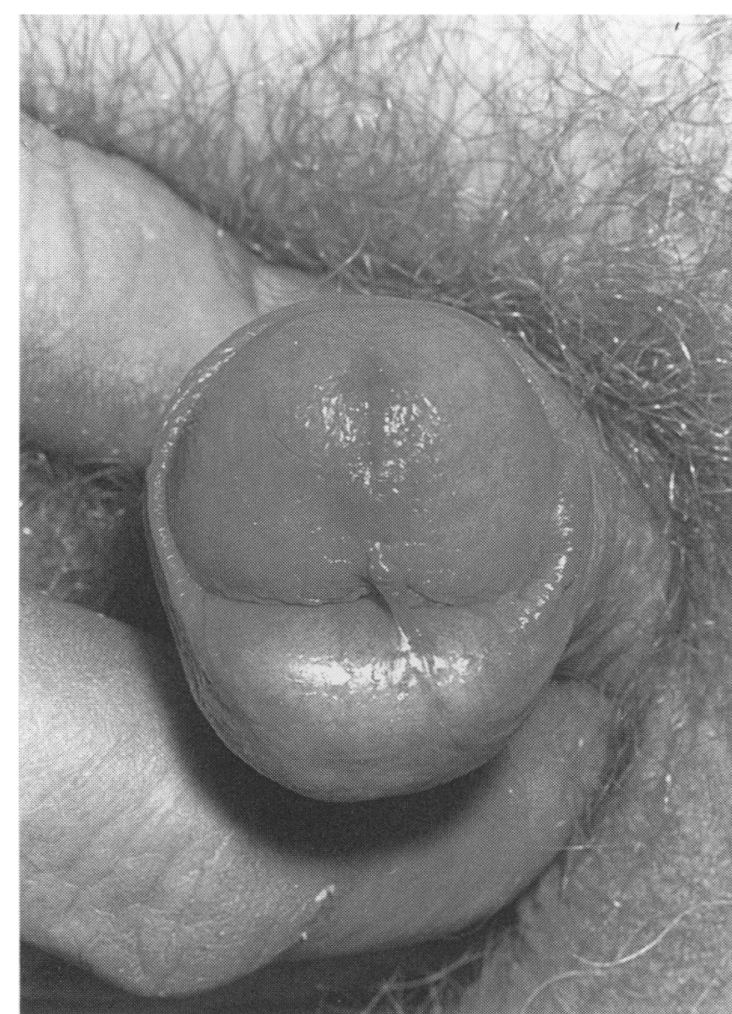

Figure 1 The penis showing a foreign body within the posterior part of the penis with fibrosis. regular girlfriend of 3 years' duration. He gave no history suggestive of sexual dysfunction.

General examination was unremarkable. On genital examination a mucopurulent discharge was noted from the external urethral meatus, and there was a hard, fibrotic area in the posterior distal one-third of the penile shaft (fig 1). The rest of the examination was unremarkable. When the patient was therefore asked about that particular area, he was extremely embarrassed and hesitated before disclosing the following part of the history. Twelve years previously his ex-wife had inserted a cosmetic mascara brush through the penile urethra, and when she attempted to remove it, the end of the brush remained in situ. He was too embarrassed to seek medical advice, and hoped that it would cause no problems and eventually come away.

The urethral swab for microscopy showed 10 pus cells per high powered field, and urinalysis showed a small amount of blood and protein in the urine. Tests to exclude chlamydia, gonorrhoea and syphilis were negative. $\mathrm{He}$ was commenced on a course of oxytetracycline, $500 \mathrm{mg}$ twice a day for 10 days and penile ultrasonography was carried out in order to establish the position of the foreign body (fig 2). This showed curvilinear strong echoes coming from the foreign body which was lying adjacent to the urethra. These echoes extended out into the corpus cavernosa and not just the corpus spongiosum.

He was referred for a urological opinion and the foreign body was surgically removed via a direct cut through the corpus spongiosum into the diverticulum. The patient made a good recovery, and was reviewed 2 months after operation when the scar seemed to be well

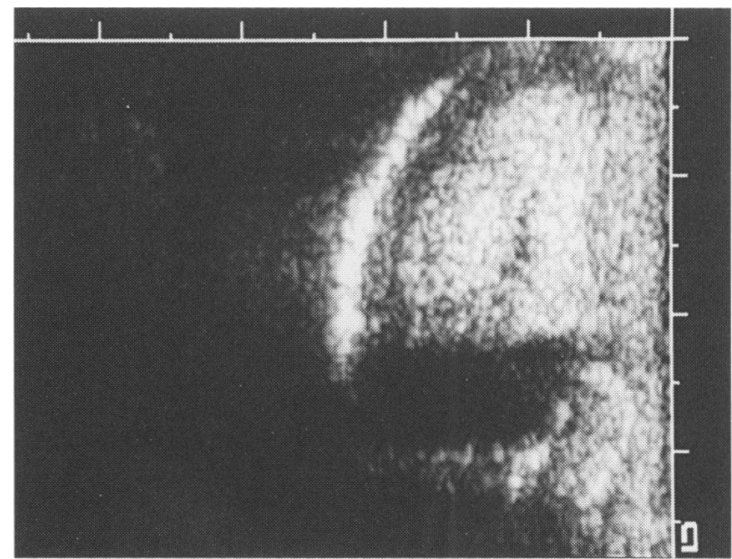

Figure 2 Ultrasonogram of the penis showing curvilinear echo of the foreign body. 
healed, he was asymptomatic and his sexual function was normal.

\section{Discussion}

This interesting case of a foreign body within the penile urethra raises a few important issues. The foreign body may remain silent for many years. It also highlights the difficulties patients may have through embarrassment, which leads them to delay seeking medical advice. A foreign body within the penile urethra, although rare, is one of the important differential diagnoses of non specific urethritis, particularly if it is recurrent.

Penile ultrasonography plays a major role in cases such as these. It determines the plane where the foreign body is lying within the penis. With that knowledge in mind, patients can be properly counselled prior to the operation and the risk can be assessed accordingly. In this case, the foreign body was lying within the diverticulum of the urethra, and had not eroded outside the urethral mucosa.

There has been much literature reporting similar cases, which shows the wide diversity of objects being inserted through the urethra into the lower urinary tract. ${ }^{2-5}$ Management of these cases can be difficult. The main objective is complete extraction and removal of the foreign body without compromising erectile function. It was difficult to remove this object via the urethra, not only because it was impossible to manipulate from the diverticulum into the urethra but also it was not feasible to extract such a large object via the urethral meatus without causing considerable damage. Hence, an incision into the corpus spongiosum had to be made.

One of the difficulties of a foreign body which remains in situ for a long time is the intense fibrotic reaction of the surrounding tissue and the incrustation of some components of urine around it. One would expect that, had this patient presented earlier, removal of the foreign body might have been possible via the urethra by endoscopy. ${ }^{67}$

1 Eckford D, Persad A, Brewster SF, and Gingeil JC. Intravesical foreign body: five-year review. $B \mathcal{F}$ Urol 1962; $69: 41-5$

2 Abdulla MM. Foreign body in the bladder. Br $\mathcal{F}$ Urol 1990; 65:420.

3 Kelly SB, Young MR. Blu-tack in the bladder. Br 7 Urol 1988;61:94-5.

4 Wenderoth U, Jonas U. Masturbation injuries. Eur Urol 1980;6:312-3.

5 Péc J, Straka S, Novomeský F, Kliment J, Péc M, Lazárová $Z$. Mechanical urethritis and ascendent genitourinary infections due to sexual stimulation of the urethra by infections due to sexual stimulation of the urethra by inserted

6 Schnall RJ, Baer HM, Seidman EJ. Endoscopy for removal of unusual foreign bodies in urethra and bladder. Urology 1989;34:33-5.

7 Vigués JF, Franco ME, Rodriguez TJ et al. Cuert extraño uretral. Act Urol Esp 1989;13:140-1. 